\title{
Defining the change of meshing rigidity caused by a crack in the gear tooth's foot
}

\author{
P. Czech $^{1 *}$, P. Folęga ${ }^{1}$, G. Wojnar ${ }^{1}$ \\ ${ }^{1}$ Faculty of Transport, Silesian University of Technology, Katowice, Poland \\ "Corresponding Author: e-mail:piotr.czech@polsl.pl
}

\begin{abstract}
In this paper, research results concerning the influence of the cracks at the base of the tooth of wheel on the change of the wheel rigidity is presented. In order to achieve this, a series of experiments was conducted with the use of models FEM and BEM. The correctness of the models was verified with the use of analytic method, whereas the final results were confirmed in a research experiment conducted on the endurance machine MTS. The achieved results enabled the conduction of research devoted to the possibility of use of simulation models of toothed gears to get the teaching data for artificial neural networks. The best of neural networks correctly worked during tests with real data.
\end{abstract}

Keywords: gearbox, FEM, BEM, stiffness

\section{Introduction}

The meshing rigidity according to the ISO/DIS 6336 norm is defined as the ratio of the increase of the normal strength to the increase of the deformation existing in the buttress of pairs of teeth with the unitary width of the non-deviation gear. The deformation is determined in the perpendicular direction to the tooth profile in the front intersection.

The meshing rigidity is dependent on the toothed wheels geometry and the physical properties of the materials they are constructed of. The main factors influencing the values of meshing rigidity are (Jaśkiewicz and Wąsiewski, 1992):

- the data concerning the meshing (number of teeth, the coefficient of the profile shift, the profile of the reference, etc.),

- the load value,

- roughness and waviness of the sides of tooth,

- elasticity module.

In the ISO/DIS 6336/1 norm a number of methods of meshing rigidity marking are given and they differ from each other mainly in terms of" the calculation precision of results. The most precise method of meshing rigidity marking is the A method, according to which in the conducted analysis all factors having influence on it should be taken into account. The methods in this group are numeric calculation methods, such as finite elements method (FEM) and boundary elements method (BEM). In this paper, both mentioned methods will serve as a tool to mark the meshing rigidity in both a proper and damaged gear. The use of the numeric methods in the tests of damages in toothed gears may be found in (Chaari et al, 2009, Ciavarella and Demelio, 1999, Ding et al, 1995, Howard et al, 2001, Kramberger et al, 2004, Pehan et al, 1997, Pehan et al, 2008, Zouari et al, 2007).

In the literature, one may find the simplified methods of meshing rigidity marking. Among them is the suggestion in (Müller, 1986) which concerns a method of analytic marking of the meshing rigidity. That method, however, has serious limitations preventing the conduction of a complete experiment. This limitation is the possibility to mark the value of the meshing rigidity only for the undamaged teeth of the toothed gears. In this paper that method was use to verify the numeric models FEM and BEM. In addition, the experimental verification of the results was conducted on the endurance machine, MTS. 


\section{Analytic method of marking the meshing stiffness}

In the paper (Müller, 1986), the following analytic way of marking the meshing stiffness was suggested:

- defining the material constants, the geometry of the tooth and the size of the load,

- marking the deflection of the tooth in the chosen points of the normal strength application to the profile,

- marking the deflection of the co-operating tooth in the previously assumed points of strength application (teeth co-operation),

- calculation of the flattening of the surface of both teeth in the successive points of contact,

- marking the total deformation of the pair of teeth,

- marking the meshing rigidity in separate defined co-operation points.

Marking of the changes in rigidity of a tooth in a pinion, the wheel and the meshing is conducted with the use of the dependence:

$$
\begin{aligned}
& C_{1}=\frac{F}{w_{1}} \\
& C_{2}=\frac{F}{w_{2}} \\
& C_{Z}=\frac{F}{\frac{F}{C_{1}}+\frac{F}{C_{2}}}
\end{aligned}
$$

where:

$F$ - unitary load strength $\mathrm{N} / \mathrm{mm}$,

$w_{1}$ - deflection of the tooth in pinion $\mu \mathrm{m}$,

$w_{2}$ - deflection of the tooth of wheel $\mu \mathrm{m}$,

$C_{1}$ - rigidity of the tooth of pinion $\mathrm{N} / \mathrm{mm} \mu \mathrm{m}$,

$C_{2}$ - rigidity of the tooth of wheel $\mathrm{N} / \mathrm{mm} \mu \mathrm{m}$,

$C_{z}$ - meshing rigidity $\mathrm{N} / \mathrm{mm} \mu \mathrm{m}$.

Because this method does not enable to mark the tooth rigidity with a cracked base, it was used only to verify the numeric models of FEM and BEM. In order to verify the FEM and BEM models, the results achieved with the use of them were compared with the results achieved with the use of Müller analytic method.

An example presented in (Müller, 1986) was used, with the following assumptions:

- number of teeth of pinion $\mathrm{z}_{1}=20$,

- number of teeth of a wheel $\mathrm{z}_{2}=35$,

- coefficient of the shaft of the pinion profile $\mathrm{x}_{1}=0,3$,

- coefficient of the shaft of the wheel profile $\mathrm{x}_{2}=0,1$,

- thickness of the pinion $\mathrm{s}_{\mathrm{fl}}=2,033$ (this value corresponds with the value of the toothed gear module),

- wheel thickness $\mathrm{s}_{\mathrm{f} 2}=2,077$ (this value corresponds with the value of the toothed gear module),

- angle of the profile $\alpha=20^{\circ}$,

- tip clearance $c_{0}=0,2$ (this value corresponds with the value of the toothed gear module),

- the height of the tool head $\mathrm{h}_{\mathrm{a} 0}=1,25$ (this value corresponds with the value of the toothed gear module),

- scale on the principal circle $\mathrm{p}_{\mathrm{b}}=0,282$ (this value corresponds with the value of the toothed gear module),

- number of contact $\varepsilon_{\alpha}=1,525$,

- unitary load $\mathrm{Q}=4 \mathrm{MPa}$.

The comparison of the meshing rigidity marked with FEM and BEM method with the results achieved with the use of Müller analytic method are shown in Table 1 and in Figure 1.

Additionally, in Table 1, the percentage differences $\left(\Delta_{\%}\right)$ between the results achieved in case of FEM and BEM method and the Müller analytic method are presented. In the analysis of the meshing stiffness values marked with the use of numeric methods FEM and BEM and the Müller analytic method one may state their conformity in quality and quantity. The differences in the achieved results may result from not taking into account in numeric calculations the contact effects, which is the flattening of the teeth surfaces. 
Table 1. Meshing rigidity marked with the use of Müller analytic method, FEM and BEM

\begin{tabular}{|c|c|c|c|c|c|}
\hline \multirow{2}{*}{$\begin{array}{l}\text { Point of co-operation } \\
\text { on the contact line }\end{array}$} & \multicolumn{5}{|c|}{ Meshing rigidity marked with the use of: } \\
\hline & $\begin{array}{c}\text { Müller } \\
(\mathrm{N} / \mathrm{mm} \mu \mathrm{m})\end{array}$ & $\begin{array}{c}\text { FEM } \\
(\mathrm{N} / \mathrm{mm} \mu \mathrm{m}) \\
\end{array}$ & $\begin{array}{l}\Delta_{\%} \\
(\%) \\
\end{array}$ & $\begin{array}{c}\text { BEM } \\
(\mathrm{N} / \mathrm{mm} \mu \mathrm{m}) \\
\end{array}$ & $\begin{array}{l}\Delta_{\%} \\
(\%) \\
\end{array}$ \\
\hline 1 & 12,573 & 12,126 & 3,5 & 11,228 & 10,7 \\
\hline 2 & 14,363 & 14,414 & 0,3 & 13,840 & 3,6 \\
\hline 3 & 15,664 & 15,622 & 0,3 & 15,145 & 3,3 \\
\hline 4 & 16,369 & 16,552 & 1,1 & 15,970 & 2,4 \\
\hline 5 & 16,450 & 16,822 & 2,3 & 16,625 & 1,1 \\
\hline 6 & 15,943 & 16,366 & 2,6 & 15,449 & 3,1 \\
\hline 7 & 14,936 & 15,147 & 1,4 & 14,526 & 2,7 \\
\hline 8 & 13,551 & 13,898 & 2,7 & 13,157 & 2,9 \\
\hline 9 & 11,920 & 11,460 & 3,9 & 10,432 & 12,5 \\
\hline
\end{tabular}

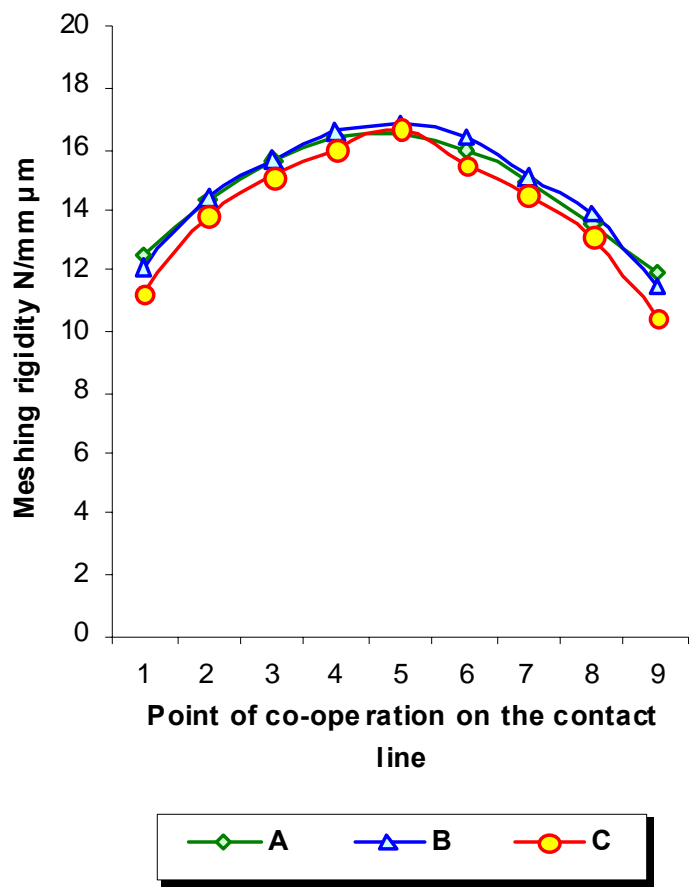

Figure 1. Meshing rigidity marked with the use of: A - Müller, B - FEM, C - BEM

\section{Marking of the meshing stiffness with the use of finite elements method}

Marking of the meshing stiffness with the use of FEM method enables to take into account all factors appearing in contact of teeth in toothed gears. Such complete approach to the issue causes numeric difficulties and rather long numeric calculation time. That is why after conduction of a number of numeric experiments a simplified method of marking the meshing stiffness based on the assumptions of the analytic method shown in paper (Müller, 1986) was worked out.

After generating the profile of the pinion tooth and the wheel, the deformations are marked in points of strength application, and next the rigidity changes of a single tooth in a radius function separately for the pinion and for the wheel. Next, having in mind the course of rigidity changes of single teeth it is possible to mark the meshing rigidity of one pair of teeth in a randomly chosen point on the contact line. Knowing the meshing rigidity of one pair of teeth it is possible to mark the meshing rigidity in a multi-pair contact.

The geometry of the profile of a pinion tooth and the wheel was marked as a set of points coordinates on specially created software prepared by Transport Faculty of Silesian University of Technology. This software enables, in accordance with the assumed pinion or wheel parameters (module, number of teeth, correction, etc.) to mark the curve describing the evolvent part of the tooth profile and the shape of the tooth foot according to (Müller, 1996).

The load method and the tooth support method assumed in the numeric calculations is presented in Figure 2. 


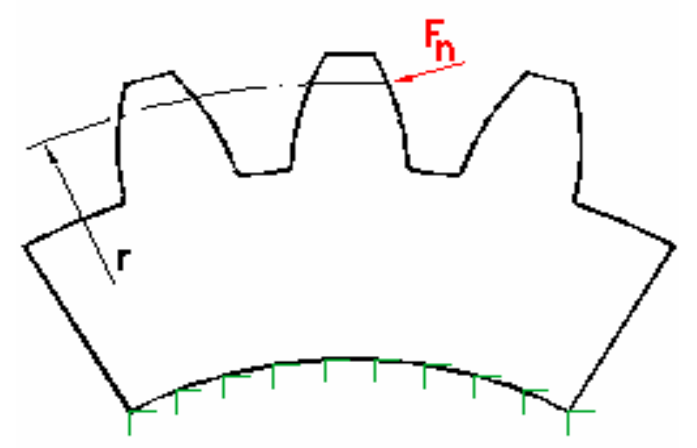

Figure 2. The load method and the tooth support method

In the calculations three teeth of a wheel were used with fastened rim and normal strength to the profile loading the middle tooth. The unitary load strength was applied in successive points of the tooth profile. Those points were placed on the corresponding radii of the gear, being the equivalent of various points of teeth co-operation on the contact line.

In order to create the numeric model of the pinion and the wheel the program $\operatorname{Cosmos} / \mathrm{M}$. The net with the appropriately chosen density was constructed of elements type PLANE2D.

The created numeric model took into account the real shape geometry of a tooth and the deformation of the toothed wheel rim. In the conducted calculations, during marking the meshing rigidity, the flattening of the surface of both teeth in successive points of contact caused by the touch of those surfaces was not taken into consideration.

In order to mark the influence of the crack in a tooth base on the meshing rigidity such wheels were used with parameters corresponding to the assumed during the simulation research with the use of dynamic model of a gear and the tests on the rotating power post FZG (Czech, 2006). Gear specifications are presented in the Table 2.

Table 2. Specifications of gearbox

\begin{tabular}{|l|c|}
\hline \multicolumn{1}{|c|}{ Parameter } & Value \\
\hline Number of pinion teeth & $\mathrm{z}_{1}=16$ \\
\hline Number of wheel teeth & $\mathrm{z}_{2}=24$ \\
\hline Obliquity angle & $\beta=0^{\circ}$ \\
\hline Addendum modification coefficient & $\mathrm{x}_{1}=0,8635$ \\
\hline Gear modification coefficient & $\mathrm{x}_{2}=-0,5$ \\
\hline Main pressure angle & $\alpha=20^{\circ}$ \\
\hline Nominal module & $\mathrm{m}_{\mathrm{n}}=4.5 \mathrm{~mm}$ \\
\hline Contact ratio & $\varepsilon_{\alpha}=1,32$ \\
\hline Addendum coefficient & $\mathrm{h}_{\mathrm{ao}}=1$ \\
\hline Tip clearance coefficient & $\mathrm{c}_{\mathrm{o}}=0,25$ \\
\hline Wheel width & $\mathrm{b}=20 \mathrm{~mm}$ \\
\hline
\end{tabular}

The crack in the foot of the tooth was modelled as an undercut with parameters presented in Figure 3.

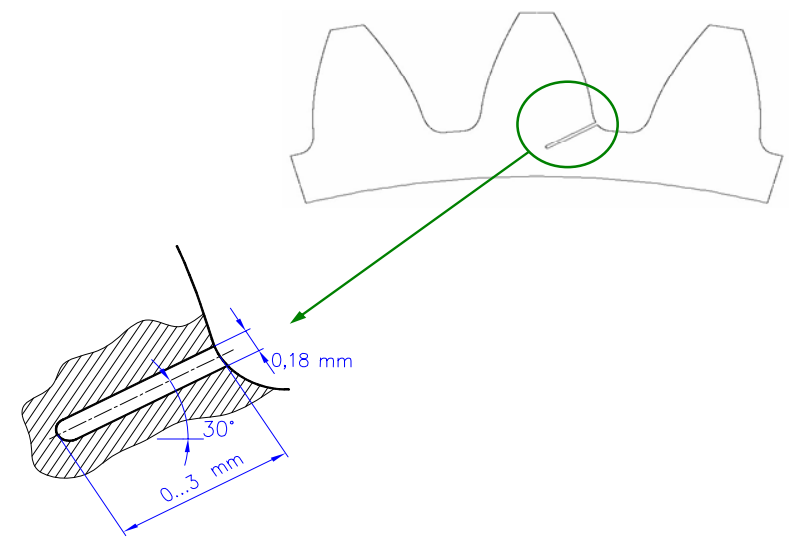

Figure 3. Way of modelling the crack in the tooth foot 
The position of the undercut was chosen in the point where the biggest concentration of the stress appeared in the foot of tooth on its stretched side (Ciavarella and Demelio, 1999, Kramberger et al, 2004, Müller, 1972, Pehan et al, 1997). The width and the depth of the gap were in accordance with the one assumed during tests on the real object of the working gear on FZG stand (Czech, 2006).

The tests were conducted for the correct gear and the gear with a defect in the form of a crack in the foot of wheel tooth.

The example results achieved with the use of FEM method of the deflection of the tooth without damage and with damage in the form of crack in the foot of the tooth are shown in Figure 4.

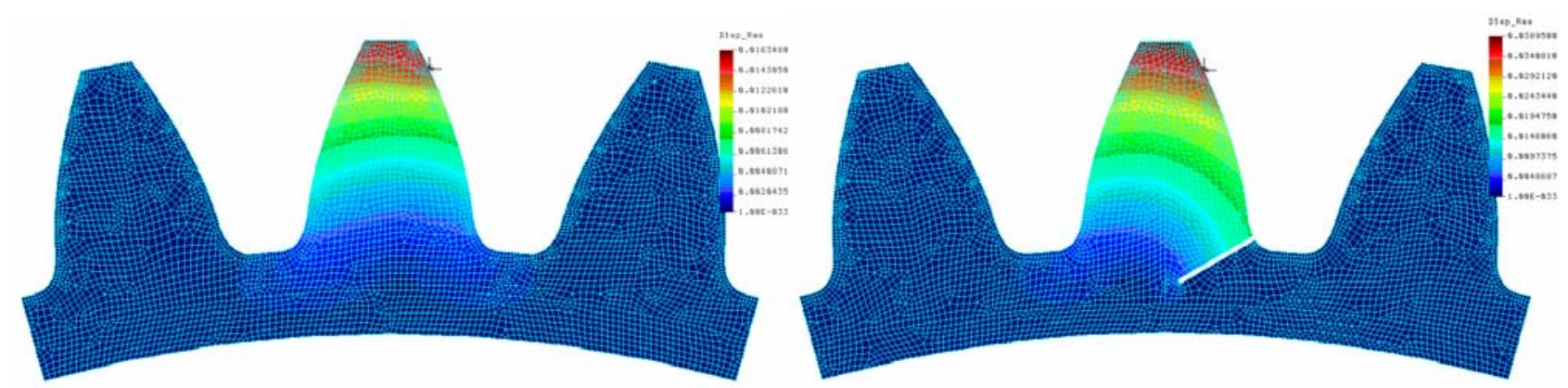

Figure 4. The tooth deflection marked with the use of FEM method under the influence of applied unitary strength for an undamaged tooth and a tooth with a modelled crack in the foot

The rigidity of the pinion, the wheel and the meshing marked with the use of FEM method are shown in Figure 5.
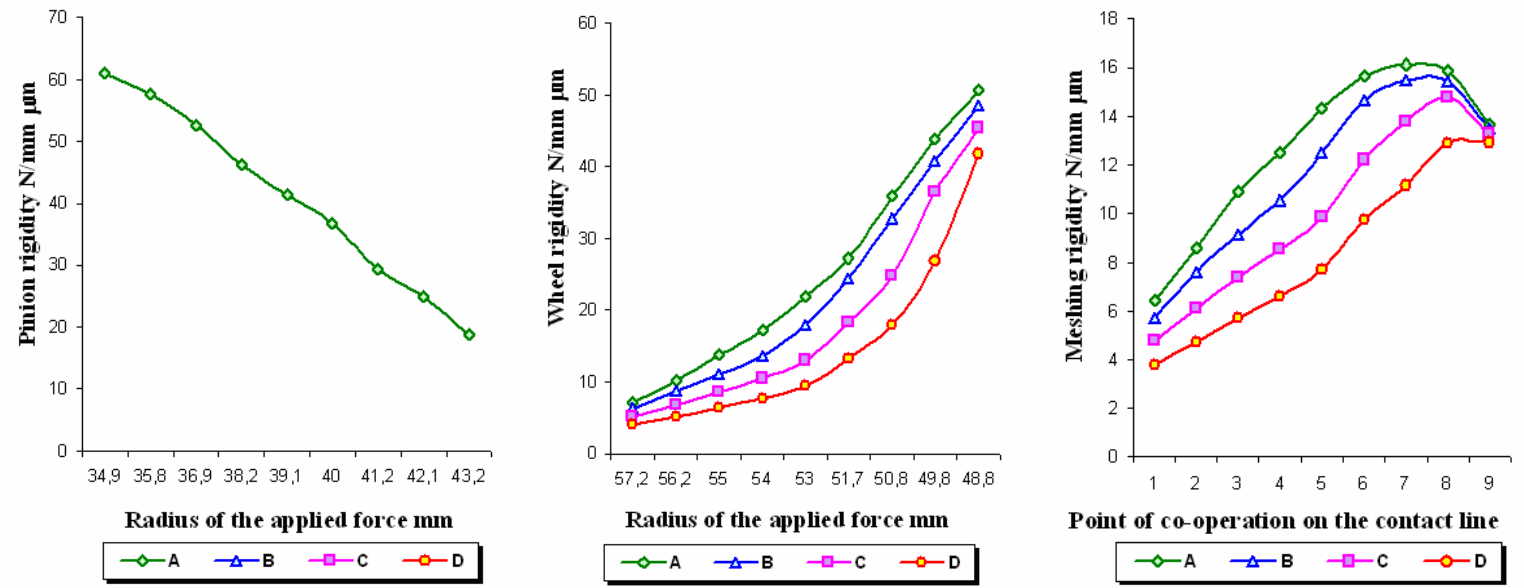

Figure 5. Marked with the use of FEM method: pinion rigidity, wheel rigidity and meshing rigidity, with the depth of the undercut: $\mathrm{A}-0 \mathrm{~mm}, \mathrm{~B}-1 \mathrm{~mm}, \mathrm{C}-2 \mathrm{~mm}, \mathrm{D}-3 \mathrm{~mm}$

The conducted analyses confirmed the correctness of the assumption in paper (Czech, 2006) about the decrease of meshing rigidity in case of appearing crack of the tooth base.

\section{Marking of the meshing rigidity with the use of boundary elements method}

In order to mark the meshing rigidity with the use of BEM method, special software was used, created for this purpose on the Faculty of Transport of Silesian University of Technology. This software enables to generate any profile of the teeth of a wheel and the calculation of the rigidity for wheels without damages, as well as with appearing damage in the form of a crack in the tooth base. The assumptions of the tests were the same as the ones for FEM method.

The software, which was used, enables the refinement of the points of the tooth profile in places of biggest stresses concentration. This application enables the analysis of the flat state of the deformation, making it possible to take into the concentration directly the points describing the profile of the tooth as kinematic pairs of the boundary elements. In the tests the elements with three kinematic pairs and square functions of shape were used. The support method and the way of force application were in accordance with the ones assumed in meshing rigidity tests with the use of FEM method.

The example results of the tooth deflection under the influence of the applied unitary strength, achieved with the use of BEM method are shown in Figure 6. 


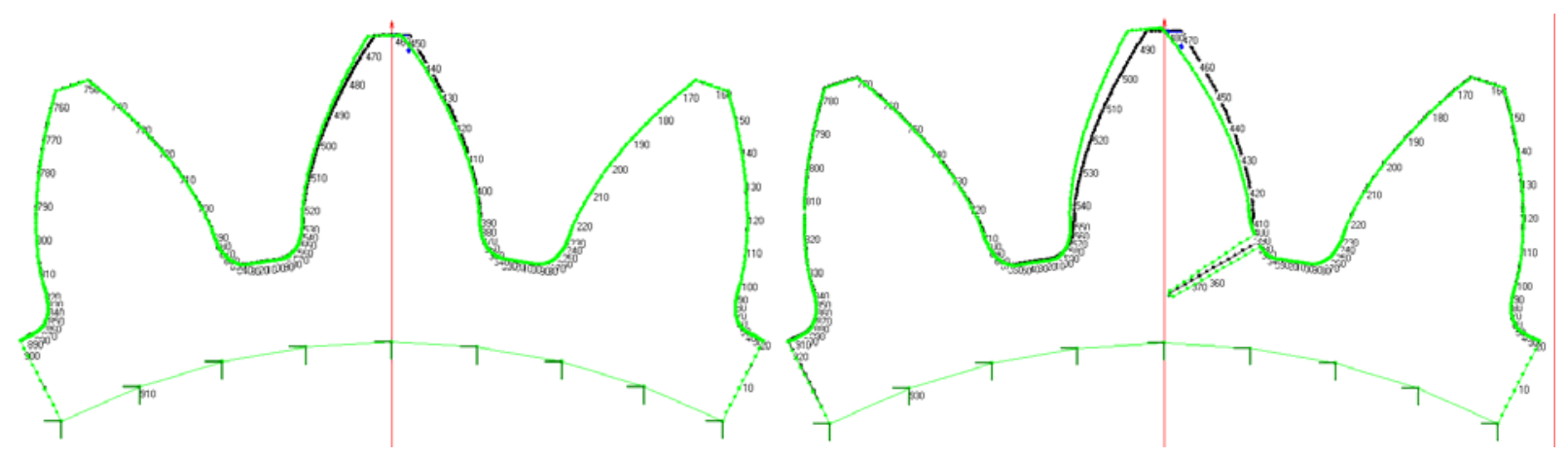

Figure 6. The tooth deflection marked with the use of BEM method under the influence of applied unitary strength for an undamaged tooth and a tooth with a modelled crack in the foot (scale $=10: 1)$

The conducted experiment was repeated for an undamaged wheel and for a wheel with an undercut in the foot of the tooth. The undercut was done on the depth of 1,2 and $3 \mathrm{~mm}$, which was in accordance with the tests on a real object of a working gear on a rotating power post (Czech, 2006).

The results for pinion rigidity, wheel rigidity and meshing rigidity, achieved after BEM analysis, are presented in Figure 7.
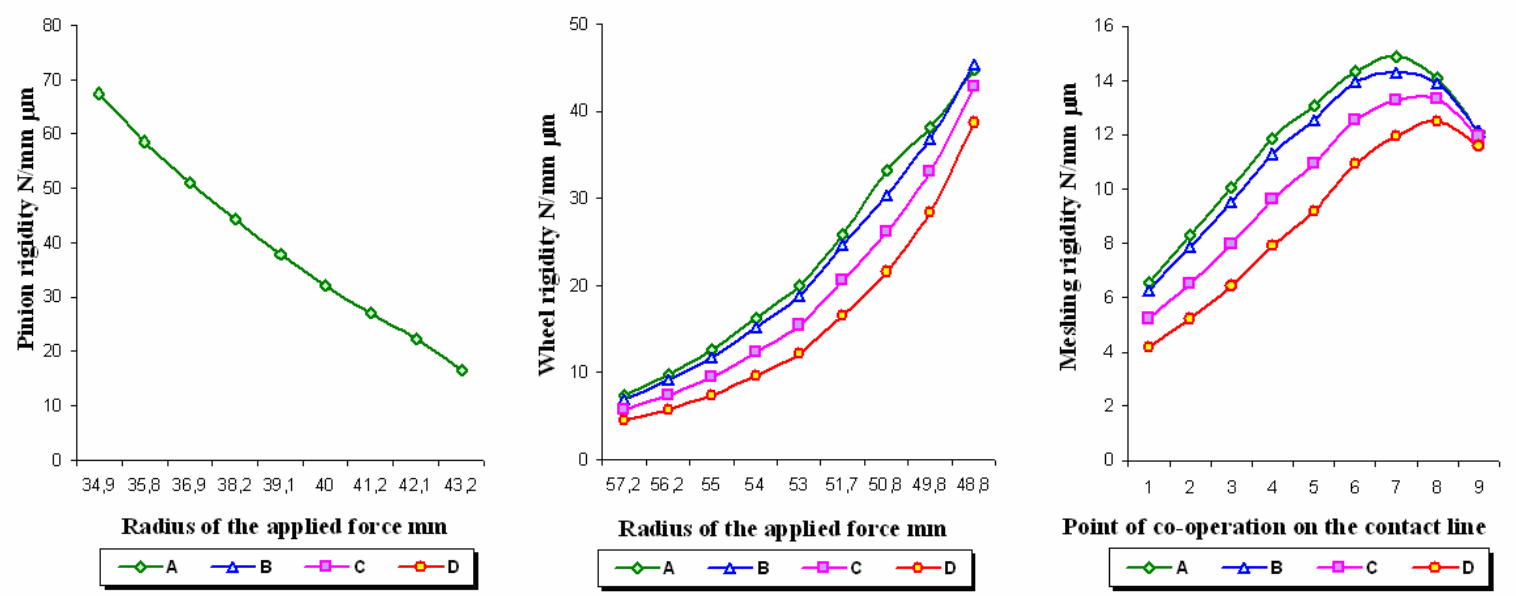

Figure 7. Marked with the use of BEM method pinion rigidity, wheel rigidity and meshing rigidity, with the depth of the undercut: A - $0 \mathrm{~mm}, \mathrm{~B}-1 \mathrm{~mm}, \mathrm{C}-2 \mathrm{~mm}, \mathrm{D}-3 \mathrm{~mm}$

The assumptions presented in paper (Czech, 2006) concerning the decrease of the meshing rigidity in case of the crack appearing at the base of the tooth were confirmed by the achieved results.

\section{Experimental verification of the results}

The aim of the tests was the experimental verification of the designed numeric model of a toothed wheel. The machining station tests were conducted on a resistance machine MTS-810 with a power range up to $50 \mathrm{kN}$ (Figure 8).

The use of the MTS machine in tests enables the conduction of the thermo-mechanical endurance tests. The machining station is built of:

- extensometers suitable for tests in room temperature and in high temperatures,

- resistance furnace type MTS 653 02.A Furnace with temperature up to $1200^{\circ} \mathrm{C}$,

- heating chamber up to $500^{\circ} \mathrm{C}$,

- inductive heater by LEPEL company, type DWGT-504-279,

- system Test Star II and Test WARE SX for digital operation of endurance machines,

- system for heat fatigue test.

System of digital operation Test Star II enables the independent steering of two quantities simultaneously. It gives possibility to conduct heat fatigue tests by independent steering of the heat cycle and the mechanic load. The load may be realised by steering of one quantity only: power, shift or deformation. 


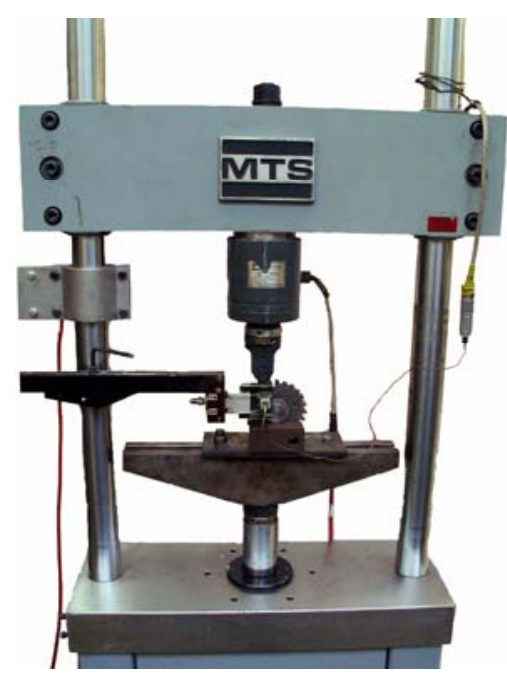

Figure 8. The MTS-810 machine

The conducted tests were performed with steering of power ranging from 0 to $7.5 \mathrm{kN}$. The power range was chosen in such a way, in order not to exceed the elastic deformation. The load was applied on the wheel tooth tip.

In the experiments the deflection in the power application point in the direction of its influence was registered with the use of extensometers joined with the registration device. Tooth load method with attached extensometer is shown in Figure 9.

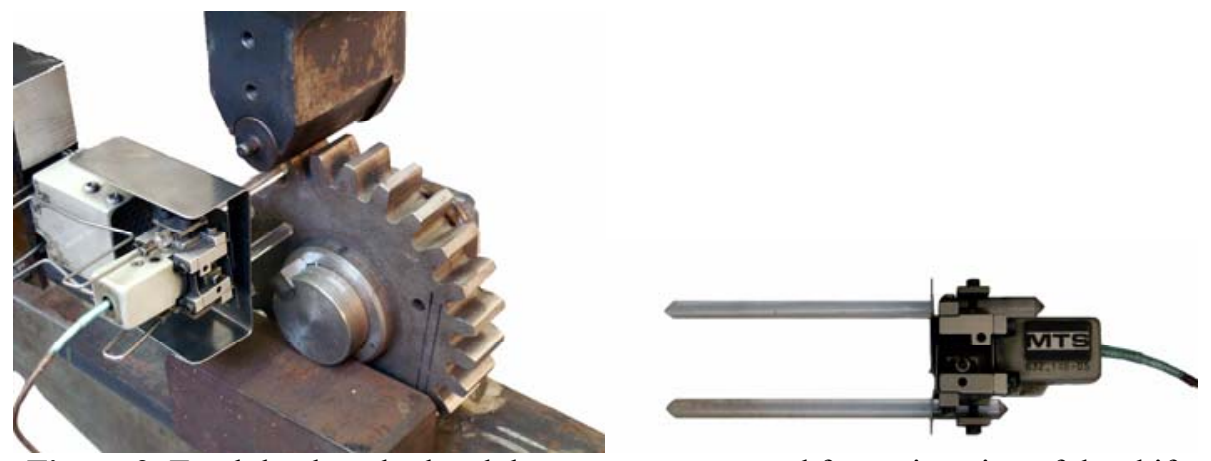

Figure 9. Tooth load method and the extensometer used for registration of the shift

The tests were conducted for an undamaged wheel and for a wheel with a modelled undercut in the tooth foot at the depth of 1,2 and $3 \mathrm{~mm}$. The parameters of the tested wheel were in accordance with the one used in dynamic model tests of a toothed gear and the conducted test on rotating power post FZG (Czech, 2006).

The achieved results of the experiment were compared with the results achieved during tests with the use of FEM and BEM and put together in Figure 10.

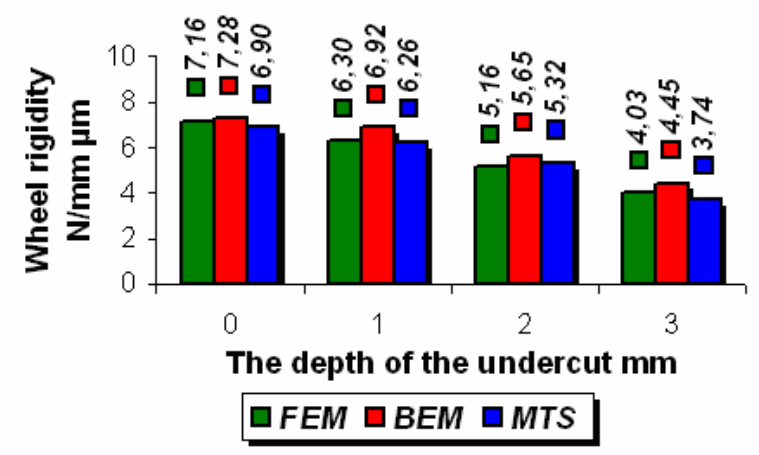

Figure 10. Rigidity of a wheel tooth marked on its tip

The conducted tests on an endurance machine MTS confirmed the correctness of the numeric experiments using FEM and BEM. 
The appearing differences may result from the applied methodology, different in case of each experiment.

\section{Conclusion}

According to the research made so far, around $60 \%$ of toothed gear failures result from tooth failure, and around $90 \%$ of these involve local failures, such as cracking at the tooth root. The cracking is accompanied by disturbance of tooth contact conditions, resulting from local change of meshing rigidity.

The key objective of the gear diagnostics procedures is to identify such process in its early stages. Non-invasive diagnostics, including vibroacoustic diagnostics, is of particular importance here.

At present, failure symptoms found in the signal, are more and more often studied with the aid of artificial intelligence methods. Such methods are resistant to interference, and allow modelling of any nonlinearities and generalization of knowledge.

On the basis of the achieved results, in paper (Czech, 2006) the following influence of the crack in the tooth foot on the change of meshing rigidity was assumed:

- $0 \mathrm{~mm}: 0 \ldots 9 \%$ change of meshing rigidity,

- $1 \mathrm{~mm} 10 \ldots 19 \%$ change of meshing rigidity,

- $3 \mathrm{~mm} 30 \ldots 40 \%$ change of meshing rigidity.

These assumptions enabled in the next part of the tests (Czech, 2006) to check the correctness of neural classifiers work, which were taught with the use of standards achieved from a dynamic model of a toothed gear working in a power transmission system. The testing process, however, was conducted using data achieved from a real gear. As a result of the conducted research it was possible to build a correctly working neural classifier of both the kind, as well as the kind and advancement of the gear damage.

In the next investigations, the artificial neural networks (eg SVM, MLP, RBF, PNN), fuzzy logic and genetic algorithms in diagnostic systems which could recognise the type and level of local damages of the teeth of the toothed gears will be used. The classifiers will be based on input data derived from acceleration signals.

\section{References}

Chaari F., Fakhfakh T., Haddar M., 2009. Analytical modelling of spur gear tooth crack and influence on gearmesh stiffness. European Journal of Mechanics - A/Solids, Vol. 28, No. 3, pp. 461-468.

Ciavarella M., Demelio G., 1999. Numerical methods for the optimization of specific sliding, stress concentration and fatigue life gears. International Journal of Fatigue, Vol. 21, pp. 465-474.

Czech P., 2006. Toothed gear troubleshooting by means of artificial intelligence. PhD Thesis. Katowice.

Ding Y., Jones R., Kuhnell B., 1995. Numerical analysis of subsurface crack failure beneath the pitch line of a gear tooth during engagement. Wear, Vol. 185, pp. 141-149.

Howard I., Jia S., Wang J., 2001. The dynamic modeling of a spur gear in mesh including friction and crack. Mechanical Systems and Signal Processing, Vol. 15, No. 5, pp. 831-853.

Jaśkiewicz Z., Wąsiewski A., 1992. Gearboxes. WKiŁ, Warszawa.

Kramberger J., Sraml M., Potrc I., Flasker J., 2004. Numerical calculation of bending fatigue life of thin-rim spur gears. Engineering Fracture Mechanics, Vol. 71, pp. 647-656.

Müller L., 1986. Gearboxes. Dynamics. WNT, Warszawa.

Müller L., 1972. Gearboxes. Strength researches. WNT, Warszawa.

Müller L., 1996. Gearboxes. Design. WNT, Warszawa.

Pehan S., Hellen T. K., Flasker J., Glodez S., 1997. Numerical methods for determining stress intensity factors vs crack depth in gear tooth roots. Engineering Fracture Mechanics, Vol. 19 No. 10, pp. 677-685.

Pehan S., Kramberger J., Flašker J., Zafošnik B., 2008. Investigation of crack propagation scatter in a gear tooth's root. Engineering Fracture Mechanics, Vol. 75, No. 5, pp. 1266-1283.

Zouari S., Maatar M., Fakhfakh T. and Haddar M., 2007. Three-dimensional analyses by finite element method of a spur gear: effect of cracks in the teeth foot on the mesh stiffness. Journal of Failure Analysis and Prevention, Vol. 7, No. 6, pp. 475-481.

\section{Biographical notes}

Dr. Piotr Czech, Dr. Piotr Folęga, Dr. Grzegorz Wojnar are assistant professors at the Silesian University of Technology, Transport Faculty, Department of Automotive Vehicle Construction. They have published several papers in various national, international conferences and journals. They are the winners of many competitions, such as the competition for the Prize of President of the Council of Ministers and for Fiat Prize.

Received December 2009

Accepted January 2010

Final acceptance in revised form January 2010 